\title{
Residual $\beta$-cell function after 10 years of autoimmune type 1 diabetes: prevalence, possible determinants, and implications for metabolism
}

\author{
Jin Cheng", Min Yin", Xiaohan Tang, Xiang Yan, Yuting Xie, Binbin He, Xia Li, Zhiguang Zhou \\ National Clinical Research Center for Metabolic Disease, Key Laboratory of Diabetes Immunology, Ministry of Education, Department of \\ Metabolism and Endocrinology, The Second Xiangya Hospital of Central South University, Changsha, China \\ Contributions: (I) Conception and design: J Cheng, M Yin, X Li, Z Zhou; (II) Administrative support: X Li, Z Zhou; (III) Provision of study materials \\ or patients: J Cheng, M Yin, X Yan, Y Xie, B He; (IV) Collection and assembly of data: All authors; (V) Data analysis and interpretation: J Cheng, X \\ Tang; (VI) Manuscript writing: All authors; (VII) Final approval of manuscript: All authors. \\ \#These authors contributed equally to this work. \\ Correspondence to: Zhiguang Zhou, PhD, MD; Xia Li, PhD, MD. National Clinical Research Center for Metabolic Disease, Key Laboratory of \\ Diabetes Immunology, Ministry of Education, Department of Metabolism and Endocrinology, The Second Xiangya Hospital of Central South \\ University, 139 Middle Renmin Road, Changsha 410011, China. Email: zhouzhiguang@csu.edu.cn; lixia@csu.edu.cn.
}

Background: Type 1 diabetes (T1D) has long been considered a progressive autoimmune disease resulting in the failure of pancreatic $\beta$-cell function and absolute endogenous insulin deficiency. However, several studies have demonstrated patients with T1D have detectable C-peptide levels long after diagnosis, which has remarkable clinical significance. Since this issue has not been systematically explored in non-Caucasian populations, we aimed to identify the prevalence of residual $\beta$-cell function and its related clinical features in Chinese long-term T1D patients.

Methods: We enrolled 109 patients with T1D for $\geq 10$ years and administered a mixed-meal tolerance test (MMTT). Fasting and postprandial C-peptide (FCP/PCP) levels were measured to evaluate the insulin secretion function of $\beta$-cells. Patients whose FCP and PCP levels were both below the lower detection limit (16.7 pmol/L) were grouped as ' $\beta$-cell function depleted', while others were thought to have 'residual $\beta$-cell function'. Demographic data, metabolic status, and diabetic complications were compared between patients with or without residual $\beta$-cell function.

Results: $38.5 \%$ of subjects retained residual $\beta$-cell function, and among those, $33.3 \%$ responded to MMTT by a two-fold or greater rise of their FCP levels. Clinical features associated with residual $\beta$-cell function were older age of diagnosis [27.5 (interquartile range:11.5-37.0) vs. 17.0 (interquartile range: 8.0-30.0) years, $\mathrm{P}=0.037$ ], lower HbA1c $(64.6 \pm 20.3$ vs. $72.4 \pm 18.5 \mathrm{mmol} / \mathrm{mol}, \mathrm{P}=0.026)$, and reduced rate of hypoglycemia (23.8\% vs. $52.2 \%, \mathrm{P}=0.003)$. Age of diagnosis was positively correlated with detectable FCP level ( $\mathrm{r}=0.393$, $\mathrm{P}=0.020)$. Individuals diagnosed after 30 years of age tended to retain residual $\beta$-cell function $(\mathrm{OR}=3.016$, $\mathrm{P}=0.044)$. We found no association between residual $\beta$-cell function and chronic diabetic complications.

Conclusions: Residual $\beta$-cell function can be found in nearly $40 \%$ of long-term patients with T1D in China and is associated with older age at diagnosis and better glucose control. The relationship between residual $\beta$-cell function and chronic diabetic complications remains to be explored.

Keywords: Type 1 diabetes (T1D); $\beta$-cell function; C-peptide

Submitted Nov 17, 2020. Accepted for publication Jan 29, 2021.

doi: $10.21037 / \mathrm{atm}-20-7471$

View this article at: http://dx.doi.org/10.21037/atm-20-7471

(c) Annals of Translational Medicine. All rights reserved. 


\section{Introduction}

Type 1 diabetes (T1D) is characterized by an autoimmunemediated progressive destruction of insulin-producing $\beta$-cells, leading to a deficiency in insulin secretion. It was classically proposed that $\beta$-cell function was profoundly impaired at the time of diagnosis, and the remnants of functional $\beta$-cells would come to a total loss within a short period of time (1). Patients would then irreversibly enter the 'brittle diabetes' stage, accompanied by drastic fluctuations in blood glucose and various diabetic complications.

However, recent studies have revealed that patients with long-standing T1D had remaining low levels of C-peptide in the blood, an indication of functional $\beta$-cells. Most well-known is the work of the Joslin Medalist Study (2) which showed that patients with T1D had detectable random C-peptide levels even after a disease duration of $>50$ years. Studies also demonstrated that even modest levels of residual $\beta$-cell function were associated with better glycemia control and fewer diabetic complications (3). These findings reconfirmed the clinical significance of residual $\beta$-cell function which was often overlooked in long-term patients with T1D, and contributed to our deeper understanding of its natural history.

Nevertheless, the majority of existing studies are focused on Caucasian populations, and data from different studies show significant variation (4-8). This issue has not been sufficiently investigated in non-Caucasian populations. China leads the world in the total number of T1D cases (9), but due to the lack of a well-established case registration system, there was a huge gap between the recognition of T1D in China and western countries. Additionally, Weng et al. recently reported that most cases of new onset T1D in China occurred among adults (9), while previous Caucasianbased studies were largely focused on cases among adolescents or children. These observations highlight the necessity of investigations focusing on Chinese long-term patients with T1D of all ages, which would help reveal the complex natural history of the disease considering its heterogeneity among different populations. We present the following article in accordance with the STROBE (Strengthening the Reporting of Observational Studies in Epidemiology) reporting checklist (available at http:// dx.doi.org/10.21037/atm-20-7471).

\section{Methods}

\section{Subjects and study design}

From October 2016 to April 2019, patients who received clinical treatment at the Endocrinology Department of the Second Xiangya Hospital of Central South University were recruited if they fulfilled the following criteria: (I) diabetes diagnosis based on the World Health Organization criteria of 1999 (10); (II) insulin-dependent from disease onset; (III) positive for at least one of the diabetes-associated autoantibodies, including glutamic acid decarboxylase antibody (GADA), insulinoma-associated 2 molecule antibody (IA-2A), and zinc transporter 8 antibody (ZnT8A); and (IV) duration of diabetes $\geq 10$ years. Patients who had a history of other types of diabetes caused by specific reasons (e.g., monogenic diabetes, disease of the exocrine pancreas, and drug or chemical-induced diabetes) or any severe disease or malignancy were excluded. This study was conducted in agreement with the Declaration of Helsinki (as revised in 2013) and was approved by the local ethics committees of the Second Xiangya Hospital (No. SCI-0282016). Individual consent for this retrospective analysis was waived.

A total of 1,123 patients fulfilled the inclusion criteria of T1D, and 947 had a disease duration $<10$ years. Of the 176 patients diagnosed over 10 years, 57 tested negative for all the three autoantibodies and 10 had no results of C-peptide testing. Finally, a total of 109 subjects were included in this study (Figure 1). At the time of initial inclusion, patients' clinical information, including demographic data, disease history, and medication history was retrospectively collected.

Height, weight, waist and hip circumference, and blood pressure were measured with a standardized procedure. Body mass index (BMI) and waist-to-hip ratio (WHR) were calculated. Levels of serum glucose, triglyceride (TG), total cholesterol (TC), high-density lipoprotein cholesterol (HDL-C), low-density lipoprotein cholesterol (LDL-C), blood urea nitrogen (BUN), uric acid (UA), and creatinine (Cr) were determined by automatic chemistry system at the core laboratory of the Second Xiangya Hospital. HbA1c was measured by high performance automated liquid chromatography (HLC-723G8, Tosoh, Japan).

\section{Mixed-meal tolerance test}

All participants attended the Second Xiangya Hospital for a standard mixed-meal tolerance test (MMTT) after an overnight fast. Short-acting insulin was not allowed on the visit day. The mixed meal was given at a dose of $6 \mathrm{kcal}$ per $\mathrm{kg}$ body weight, with a maximum dose of $360 \mathrm{kcal}$. Serum samples were taken for glucose and C-peptide assessment at 


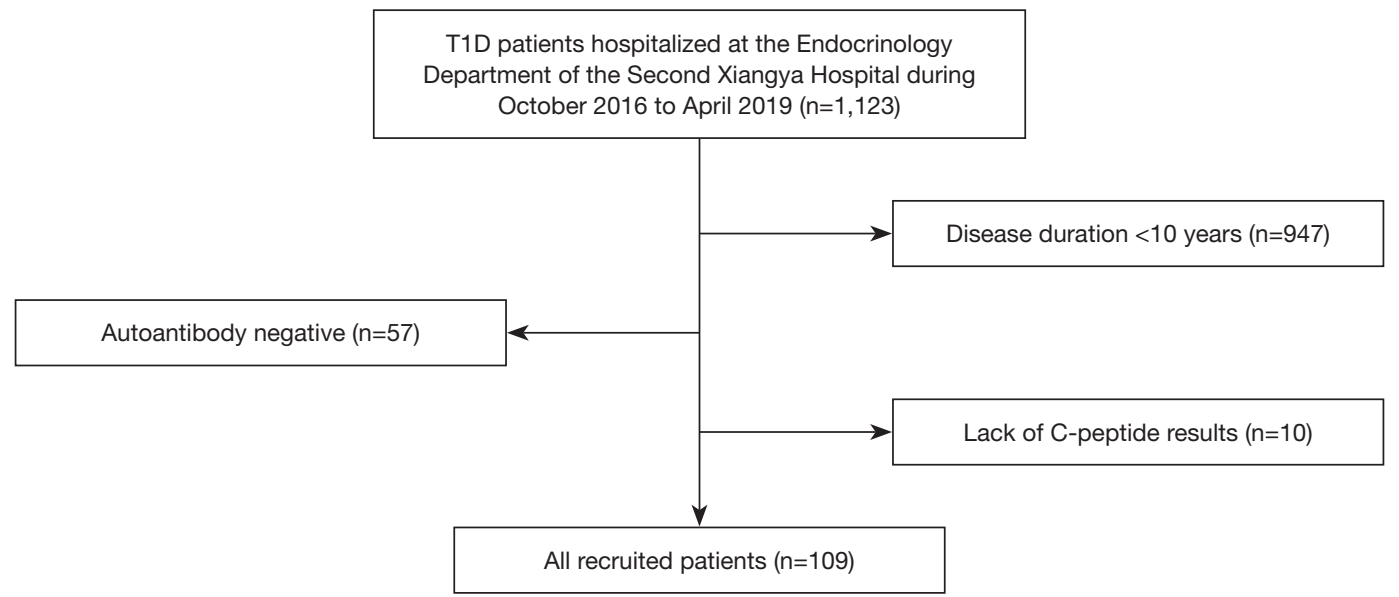

Figure 1 Flow diagram of 109 autoimmune type 1 diabetes patients with a disease duration $\geq 10$ years.

time points before and 120 min post the meal.

\section{Assessment of $\beta$-cell function}

In order to evaluate $\beta$-cell function, patients' serum C-peptide was analyzed by a chemiluminescence assay using the Adiva Centaur System kit (Siemens, Munich, Germany). The inter-assay and intra-assay variation coefficients were $3.7-4.1 \%$ and $1.0-3.3 \%$, respectively. The lower detection limit of the assay is $16.7 \mathrm{pmol} / \mathrm{L}$.

Patients whose fasting C-peptide (FCP) and postprandial $\mathrm{C}$-peptide (PCP) were both below the lower detection limit were classified as ' $\beta$-cell function depleted', while others with detectable FCP or PCP levels were thought to have 'residual $\beta$-cell function'. Patients with PCP/FCP ratio $\geq 2$ were defined as 'hyperglycemia responders'.

\section{GADA, IA-2A and ZnT8A assays}

GADA, IA-2A and ZnT8A were analyzed by radioligand assay in duplicate. The sensitivity and specificity in our laboratory were $78.0 \%$ and $96.7 \%$ for GADA, $74.0 \%$ and $96.7 \%$ for IA-2A, and $70.0 \%$ and $98.9 \%$ for $\mathrm{ZnT} 8 \mathrm{~A}$, respectively. The positive cutoff values for GADA, IA-2A, and $\mathrm{ZnT}$ 8A were an antibody index of $0.05,0.02$, and 0.01 , respectively. The serum samples of patients with positive antibodies were assayed again within a week to confirm their positivity and avoid false positives. The assay has been validated by the Islet Autoantibody Standardization Program 2012 and sponsored by the Immunology of Diabetes Society.

\section{HLA genotyping}

Genomic DNA was extracted from anticoagulated peripheral blood using the phenol-chloroform method. HLA- DRB1, DQA1 and DQB1 genotypes were defined by DNA analysis using PCR to amplify exon 2 of the DRB1, DQA1 and DQB1genes, followed by standard DNA sequencing-based genotyping. The definition of HLA-susceptible haplotypes in the Chinese population was designated according to the report in LADA China Study conducted by Luo et al. (11). The Chinese-specific HLAsusceptible haplotypes were designated as DR3 (HLADRB $1 * 0301-\mathrm{DQA} 1 * 0501-\mathrm{DQB} 1{ }^{*} 0201$ ), DR4(HLADRB1*0405-DQA1*0301-DQB1*0302, HLA-DRB1*0405DQA1*0301-DQB1*0401), and DR9 (HLA-DRB1*0901DQA1*03-DQB1*0303). The Chinese-specific HLAsusceptible genotypes for T1D were DR3/DR3, DR3/DR9 and DR9/DR9.

\section{Definition of metabolic syndrome (MetS)}

MetS was defined using the 2017 Chinese Diabetes Society's (CDS) criteria (12), and was diagnosed when three or more of the following criteria were met: (I) abdominal obesity: waist circumference $\geq 90 \mathrm{~cm}$ in men and $\geq 85 \mathrm{~cm}$ in women; (II) hyperglycemia: FBS $\geq 6.1 \mathrm{mmol} / \mathrm{L}$ or 2 -h BS $\geq 7.8 \mathrm{mmol} / \mathrm{L}$ or previously diagnosed diabetes with treatment; (III) hypertension: blood pressure $\geq 130 / 85 \mathrm{mmHg}$ or currently under antihypertension therapy; (IV) fasting TG $\geq 1.70 \mathrm{mmol} / \mathrm{L}$; (V) fasting HDL-C $<1.04 \mathrm{mmol} / \mathrm{L}$. All patients in this study were defined to fulfill the criteria for hyperglycemia. Lipid-lowering therapies were not 
included in the criteria.

\section{Determination of acute and chronic complication status}

Assessment of Hypoglycemia: We recorded the frequency and severity of hypoglycemic episodes during the month preceding recruitment. Hypoglycemia was defined as blood glucose $\leq 3.9 \mathrm{mmol} / \mathrm{L}$, and was classified as mild, moderate and severe (13). Patients with mild hypoglycemia can be aware of their hypoglycemia and are able to deal with it themselves. Patients with moderate hypoglycemia cannot cope with their hypoglycemia alone and require assistance but can be treated orally. Patients with severe hypoglycemia are semi-awake, unconscious, or in a coma with or without convulsions, usually requiring medical treatment (glucagon or intravenous glucose).

Assessment of diabetic ketoacidosis (DKA): DKA was diagnosed in patients with marked positive blood or urine ketone, elevated blood glucose or diagnosed diabetes, decreased serum $\mathrm{HCO}^{3-}$ or blood $\mathrm{PH}<7.3$. We recorded the occurrences of DKA at disease onset and during the past one year before recruiting.

Assessment of diabetic retinopathy (DR): Diabetic retinopathy was diagnosed by an ophthalmologist, using a slit lamp and an ophthalmoscope, and the severity of DR was classified as (I) no DR; (II) non-proliferative DR; or (III) proliferative DR.

Assessment of diabetic nephropathy (DN): The diagnosis of diabetic nephropathy was based on the level of urine albumin/creatinine ratio (UACR). Patients with UACR $\geq 30 \mathrm{mg} / \mathrm{g}$ were considered to have DN. In this study, severe diabetic nephropathy was defined as exhibiting a glomerular filtration rate $(\mathrm{GFR})<45 \mathrm{~mL} \cdot \mathrm{min}^{-1} \cdot 1.73 \mathrm{~m}^{-2}$.

Assessment of diabetic peripheral neuropathy (DPN): A history of diabetes, and neuropathy at or after the diagnosis of diabetes were necessary for the diagnosis of DPN. It can be diagnosed if any one of the following examinations is abnormal: abnormal ankle reflex (or abnormal knee reflex); abnormal acupuncture pain sensation; abnormal vibration sensation or abnormal pressure sensation. If the diagnosis cannot be confirmed via the above symptoms, an electrophysiological examination should be performed to assess the nerve conduction (NC). The presence of an abnormality of NC and a symptom or symptoms, or a sign or signs of neuropathy confirms DPN. Neuropathy caused by other defined causes should be excluded.

Assessment of macrovascular complications was based on clinical records of coronary artery disease, heart attack bypass graft surgery or carotid atherosclerosis of participants.

\section{Statistical analysis}

Statistical analysis was performed using SPSS version 20.0 (IBM, Armonk, NY, USA). Normally distributed data were presented as mean \pm SD. Variables with a skewed distribution were reported as median (quartile range: 25th, 75 th). Categorical variables were expressed as percentages. Normally distributed data were compared by ANOVA analysis, and non-normally distributed data by Wilcoxon Rank Sum and Spearman correlation test. Categorical variables were compared using a chi-squared test or Fisher's exact test. We performed univariate analyses to compare clinical features in subjects with or without residual $\beta$-cell function. To further investigate the possible determinants of $\beta$-cell function preservation, multivariate logistic regression including relevant factors in bivariate analyses were performed. Two-sided statistical tests were performed, and a $\mathrm{P}$ value $<0.05$ was considered to be statistically significant.

We used the restricted cubic spline (RCS) analysis nested in the bivariate logistic regression analysis in univariate and multivariate analysis to examine the association of age of onset and $\beta$-cell function preservation. Three knots were used in the RCS analysis since the sample was not large. The RCS analysis was performed in R version 4.0.2 (The R Foundation for Statistical Computing, Vienna, Austria).

\section{Results}

\section{Characteristics of participants}

A total of 109 patients with T1D were included in this study, and $40.4 \%$ (44/109) were male. Their mean age was 35.0 (quartile range: $22.5-49.0$ ) years old, ranging from 12.0 to 75.0 years old; and their mean age of onset was 19.0 (quartile range: $10.0-34.5$ ) years old, ranging from 2.0 to 60.0 years old. Their mean disease duration was 13.0 (quartile range: $10.5-15.5)$ years, and the longest was 43.0 years. Their average $\mathrm{HbA1c}$ level was $69.3 \pm 19.5 \mathrm{mmol} / \mathrm{mol}$. The overall lipid level of participants was well controlled, while $17.4 \%$ (19/109) of subjects combined MetS. The proportion of participants receiving intensive insulin therapy was up to $99.1 \%(108 / 109)$. No significant differences in sex and age of onset were found between the included and excluded patients. 
Hypoglycemia was reported in $41.3 \%(45 / 109)$ of participants during the past month, and 4.6\% (5/109) reported severe hypoglycemia. DKA occurred in $69.6 \%$ (39/56) of patients at disease onset, and in 10.1\% (11/109) during the year before recruiting. Chronic microvascular complications were reported in $53.2 \%(58 / 109)$ of participants, including DR (43.1\%), DN (28.4\%), and DPN (38.5\%). Diabetic macrovascular complications were reported in $9.2 \%(10 / 109)$ of the participants. Additionally, $30.3 \%(33 / 109)$ of all the patients combined other autoimmune disease, including autoimmune thyroid disease (29.4\%) and autoimmune hepatitis (0.9\%).

Of all the participants who consented to the genotyping analysis, $88.2 \%$ (45/51) had HLA-susceptible haplotypes, and $31.4 \%$ (16/51) had HLA-susceptible genotypes (Table 1).

\section{Prevalence of residual $\beta$-cell function}

Of all the subjects, $38.5 \%(42 / 109)$ retained residual $\beta$-cell function, and $61.5 \%(67 / 109)$ had depleted $\beta$-cell function. When the detectable C-peptide levels were further divided into minimal (16.7-200 pmol/L) and preserved ( $\geq 200 \mathrm{pmol} / \mathrm{L}$ ), we found that the FCP levels of $67.9 \%$ (74/109), 29.4\% (32/109) and 2.7\% (3/109) of patients fell into the undetectable, minimal, and preserved range, respectively. And the PCP levels of $66.0 \%$ (72/109), $25.7 \%$ $(28 / 109)$ and $8.3 \%(9 / 109)$ of patients were undetectable, minimal, or preserved, respectively. There were 9 patients retained FCP or PCP level $\geq 200 \mathrm{pmol} / \mathrm{L}$, accounting for $8.3 \%(9 / 109)$ of the total number.

As for $\beta$-cell responsiveness to hyperglycemia, $12.8 \%$ (14/109) of the patients who underwent MMTT responded to the test with their PCP levels at least doubled from their FCP levels, accounting for $33.3 \%$ (14/42) of participants with residual $\beta$-cell function.

\section{Clinical features in patients with or without residual $\beta$-cell function}

Patients with residual $\beta$-cell function had significantly older age of onset [27.5 (quartile range: 11.5-37.0) vs. 17.0 (quartile range: 8.0-30.0) years, $\mathrm{P}=0.037$ ], lower level of HbA1c $(64.6 \pm 20.3$ vs. $72.4 \pm 18.5 \mathrm{mmol} / \mathrm{mol}, \mathrm{P}=0.026)$, and a lower rate of hypoglycemia ( 23.8 vs. $52.2 \%, \mathrm{P}=0.003$ ). Severe hypoglycemia occurred only in those with depleted $\beta$-cell function.

Interestingly, differences in prevalence or severity of diabetic chronic complications, including DN, DR, DPN or diabetic macrovascular complications were not detected. Nor did parameters including age, sex, disease duration, insulin dosage, family history, combination of other autoimmune diseases or HLA genotypes show significant differences between groups. Metabolic status of blood lipids, BUN, UA, Cr, and frequencies of DKA and MetS were similar between subjects with or without residual $\beta$-cell function (Table 1).

\section{Possible determinants of residual $\beta$-cell function}

In the multivariate regression analysis, which was adjusted for sex, BMI, disease duration and status of the three autoantibodies, age of onset maintained its association with $\beta$-cell function preservation $(\mathrm{OR}=1.037,95 \% \mathrm{CI}$ : 1.003-1.072, $\mathrm{P}=0.033$, Table 2). We then performed linear correlation analysis and found age of onset positively correlated with detectable FCP level $(\mathrm{r}=0.393, \mathrm{P}=0.020$, Figure 2). Further RCS analysis showed that age of onset linearly associated with the possibility of $\beta$-cell function preservation. The slope of the curve flattened out after the point around age of 30 after adjusting for parameters including sex, BMI, disease duration and status of the three autoantibodies (Figure 3), while no significant cutoff point of age was observed on the curve. We then stratified our subjects according to different ages of onset and observed that individuals diagnosed after 30 years old had significantly higher prevalence of residual $\beta$-cell function (52.8\% vs. $31.5 \%, \mathrm{P}=0.038)$. The OR (95\% CI) for age of onset $>30$ years was $3.016(1.030-8.827)$ after adjusting for factors including sex, BMI, disease duration and the status of three autoantibodies $(\mathrm{P}=0.044)$.

Due to the relatively large number of missing values, we failed to include the HLA genotype and the occurrence of DKA at disease onset into the multivariate analysis. We can see in subjects carrying double, single, or no HLA-susceptible haplotypes, residual $\beta$-cell function was detected in $25.0 \%(7 / 28), 35.3 \%(6 / 17)$ and $50 \%(3 / 6)$ of individuals, respectively, which showed an increasing trend. In patients carrying HLA-susceptible genotypes or not, the prevalences of residual $\beta$-cell function were $31.3 \%(5 / 16)$ and $31.4 \%(11 / 35)$. However, these differences failed to reach statistical significance whether the confounding factors were adjusted or not $(\mathrm{P}>0.05)$. The proportion of subjects with residual $\beta$-cell function was slightly lower in those with DKA at disease onset (28.2\% vs. 41.2\%), but this difference also failed to reach statistical significance $(\mathrm{P}>0.05)$. 
Table 1 Clinical features of subjects categorized by residual $\beta$-cell function

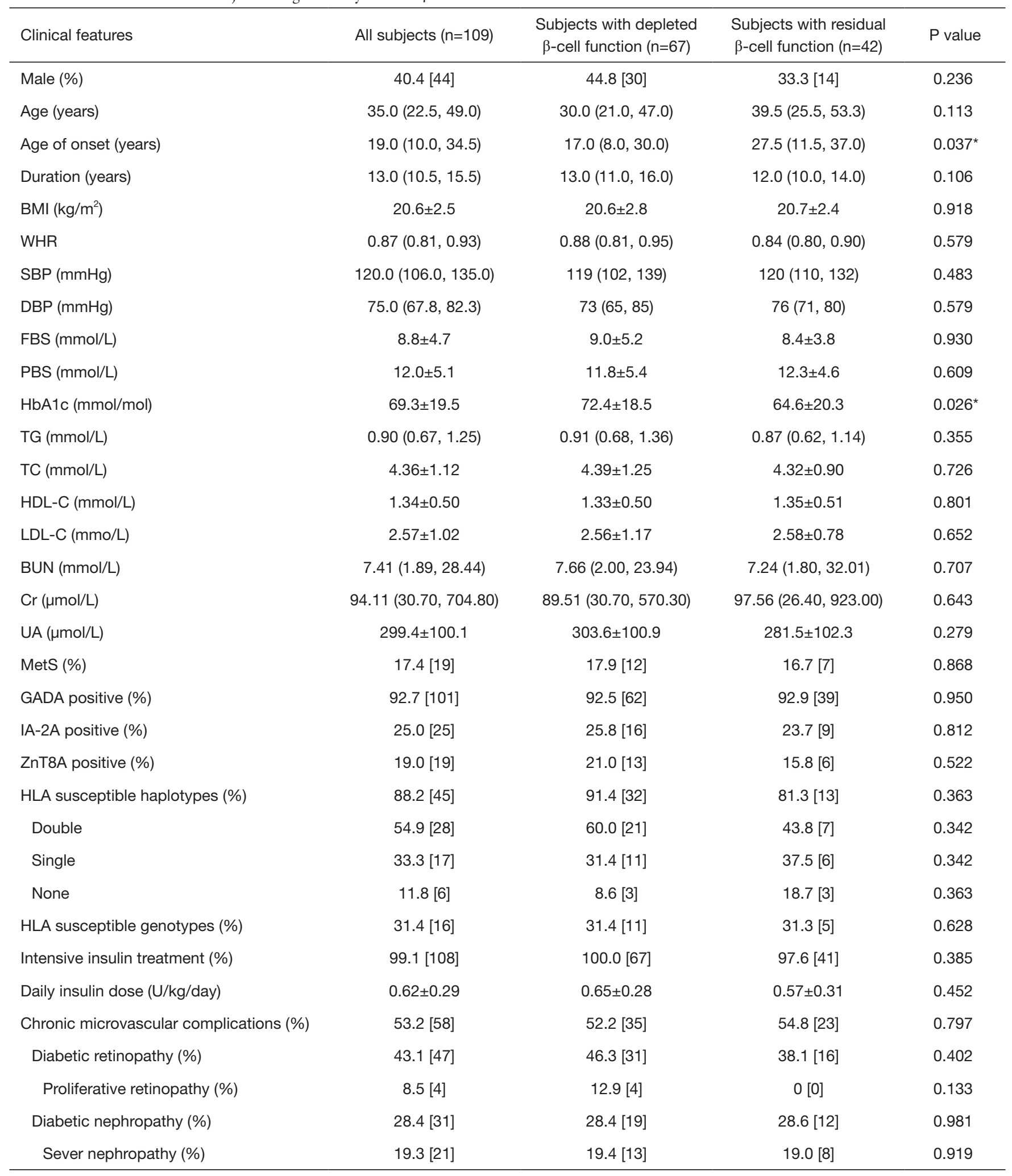

Table 1 (continued) 
Table 1 (continued)

\begin{tabular}{|c|c|c|c|c|}
\hline Clinical features & All subjects $(n=109)$ & $\begin{array}{l}\text { Subjects with depleted } \\
\beta \text {-cell function }(n=67)\end{array}$ & $\begin{array}{l}\text { Subjects with residual } \\
\beta \text {-cell function }(n=42)\end{array}$ & $P$ value \\
\hline Diabetic peripheral neuropathy (\%) & $38.5[42]$ & $37.3[25]$ & $40.5[17]$ & 0.741 \\
\hline Hypoglycemia (\%) & $41.3[45]$ & $52.2[35]$ & $23.8[10]$ & $0.003^{*}$ \\
\hline DKA before recruiting (\%) & $10.1[11]$ & $13.4[9]$ & $4.8[2]$ & 0.144 \\
\hline $\begin{array}{l}\text { Combination of other autoimmune } \\
\text { disease }(\%)\end{array}$ & 30.3 [33] & $29.9[20]$ & $31.0[13]$ & 0.903 \\
\hline ATD (\%) & 29.4 [32] & 28.4 [19] & $31.0[13]$ & 0.772 \\
\hline
\end{tabular}

Data are presented as mean \pm SD, median (25th, 75th) or \% [n], depending on variable type and distribution. Percentages reflect calculations done on data available. ${ }^{*} \mathrm{P}<0.05$, the differences between subjects with or without residual $\beta$-cell function were considered statistically significant. BMI, body mass index; WHR, waist-to-hip ratio; SBP, systolic blood pressure; DBP, diastolic blood pressure; FBS, fasting blood sugar; PBS, postprandial blood sugar; TG, total cholesterol; TC, total triglyceride; LDL-C, low density lipoprotein cholesterol; HDL-C, high density lipoprotein cholesterol; BUN, blood urea nitrogen; UA, urea; CREA, creatinine; MetS, metabolic syndrome; GADA, glutamic acid decarboxylase antibody; IA-2A, insulinoma-associated 2 molecule antibody; ZnT8A, zinc transporter 8 antibody; DKA, diabetic ketoacidosis; ATD, autoimmune thyroid disease; AILD, autoimmune liver disease.

Table 2 Possible determinants of residual $\beta$-cell function

\begin{tabular}{llll}
\hline Parameters & OR & $95 \% \mathrm{Cl}$ & P value \\
\hline Sex (male) & 0.791 & $0.303-2.068$ & 0.632 \\
Age of onset (years) & 1.037 & $1.003-1.072$ & $0.033^{*}$ \\
Disease duration (years) & 0.918 & $0.816-1.033$ & 0.154 \\
BMI $\left(\mathrm{kg} / \mathrm{m}^{2}\right)$ & 0.997 & $0.820-1.213$ & 0.976 \\
GADA positive & 0.533 & $0.083-3.439$ & 0.508 \\
IA-2A positive & 0.699 & $0.189-2.591$ & 0.592 \\
ZnT8A positive & 1.286 & $0.372-4.449$ & 0.691 \\
\hline
\end{tabular}

Multivariable logistic regression including all the variables in bivariate analysis was performed. ${ }^{*} \mathrm{P}<0.05$ was considered significant. BMI, body mass index; GADA, glutamic acid decarboxylase antibody; IA-2A, insulinoma-associated 2 molecule antibody; ZnT8A, zinc transporter 8 antibody.

\section{Discussion}

Our study is the first to show that around $40 \%$ of longterm patients with T1D in China have retained residual $\beta$-cell function, and among those, over $33.0 \%$ responded to MMTT with PCP levels at least a-double of their FCP levels. Additionally, $8.3 \%$ of participants had FCP or PCP levels greater than $200 \mathrm{pmol} / \mathrm{L}$, which was proposed by the Diabetes Control and Complications Trial (DCCT) to be associated with significant clinical benefits (14). This result is quite promising for potential immune interventions aiming at preserving the insulin secretion function of $\beta$-cells in long-term patients with T1D, especially for those with adult-onset disease, which has long been overlooked.

The proportion of patients with residual $\beta$-cell function 
in this study was comparable to or higher than a series of the former studies. Data from the T1D Exchange Clinic Network (15), the Search for Diabetes in Youth Study (16), the EDC (Pittsburgh Epidemiology of Diabetes Complications) Study (17) and the SDRNT1BIO (Scottish Diabetes Research Network Type 1 Bioresource) Study (18) revealed that the prevalence of residual $\beta$-cell function ranged from $9.7-35.4 \%$ in long-term T1D cases. Uno $S$ (8) observed all 71 Japanese T1D cases result in $\beta$-cell function failure after 15 years from diagnosis. While in the well-known Joslin Medalist Study report in 2010 (2), serum C-peptide could

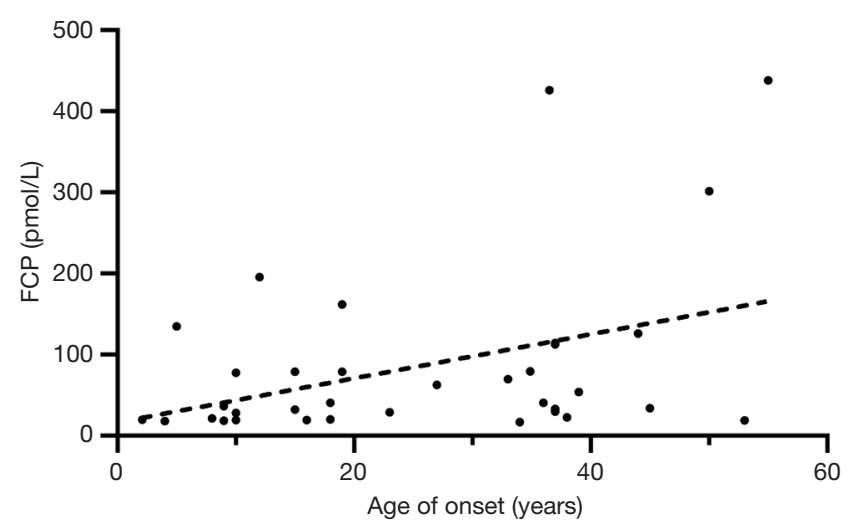

Figure 2 Association between age of onset and detectable FCP levels in long-term patients with type 1 diabetes. The curve was derived from Spearman correlation analysis. Age of onset was positively and linearly correlated with detectable FCP levels $(\mathrm{r}=0.393, \mathrm{P}=0.020)$. FCP, fasting C-peptide.

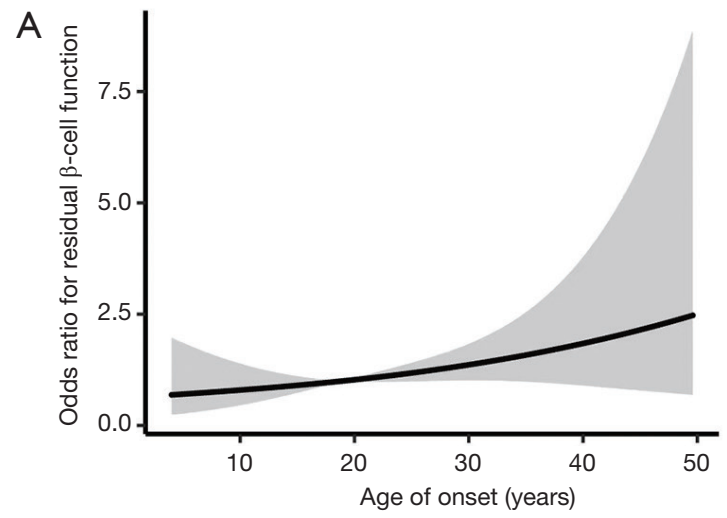

be detected in $67.4 \%$ of 411 insulin-dependent patients with $\mathrm{T} 1 \mathrm{D}$ at $\geq 50$ years after onset. Using home post-meal urine C-peptide-to-creatinine ratio (UCPCR), Oram et al. (7) found $80 \%$ of 924 participants with T1D had detectable endogenous C-peptide after a median duration of 19 years.

Variations in the above data might be attributed to several factors. First, there were differences in the selection of subjects. The Joslin Medalist Study recruited highly selected individuals who lived with T1D for more than 50 years. As reported in the $3 \mathrm{C}$ study of coverage, cost and care for T1D in China, few patients with T1D could live with the disease for more than 30 years (19). Therefore, we suspect that the extremely long course of disease in Joslin Medalist Study may exclude a proportion of patients who died with depleted $\beta$-cell function, which resulted in a relatively high proportion of $\beta$-cell function in the survivors. In addition, it was different from all the former studies that our recruited subjects with at least one positive autoantibody. The presence of autoantibodies was reportedly associated with rapid disease progression in patients with T1D $(4,20,21)$. Therefore, residual $\beta$-cell function level in our autoantibody positive subjects would be a little lower than the actual level of the whole T1D group. Thus it can be inferred that residual $\beta$-cell function in Chinese long-term T1D patients is quite considerable.

We found that older age of onset was associated with increased level of residual $\beta$-cell function, which was consistent with a number of former studies on Caucasians. Williams GM (22) and Davis AK (15) observed that subjects

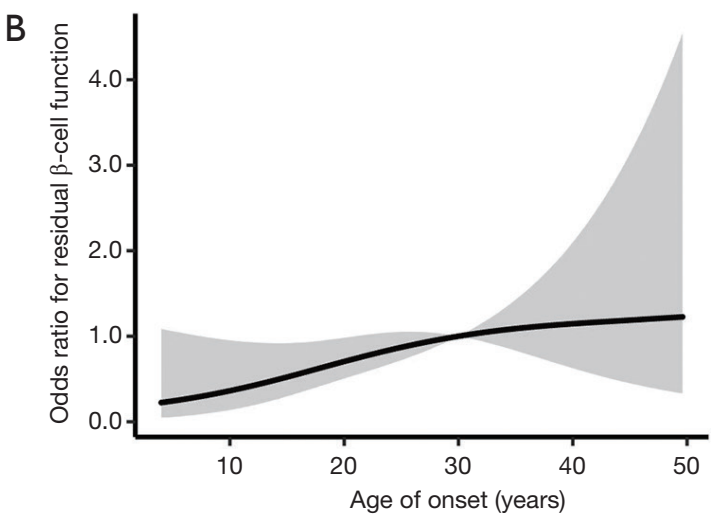

Figure 3 Association between age of onset and the possibility of $\beta$-cell function preservation in long-term patients with type 1 diabetes. The solid curves and grey areas represent the ORs and their $95 \%$ CIs for residual $\beta$-cell function preservation, respectively. Figure (A) was derived from univariate analyses, and (B) from multivariate analyses after adjusting for sex, disease duration, BMI and autoantibody status. Age of onset was positively and linearly associated with the possibility of $\beta$-cell function preservation. Although the slope of the curve flattened out after the point around age of 30, no significant cut-off point of age was observed on the curve. 
with older age of onset tended to retain persistent $\beta$-cell function long after diagnosis. The Joslin Medalist Study (2) and Oram et al. (7) reported long-term patients with T1D who were diagnosed older had higher levels of residual C-peptide. The reason for this phenomenon could be partly attributed to higher levels of residual $\beta$-cell function in older patients at the time of diagnosis (23) and partly because $\beta$-cell function depletion occurs faster in subjects with younger age of onset $(8,24,25)$, since age of onset may be associated with the strength and intensity of the underlying autoimmune process (26). In our study, the association between age of onset and $\beta$-cell function preservation still existed after adjusting for confounding factors including disease duration, BMI and autoantibody status. This indicated that age of onset may have its influence on $\beta$-cell function preservation independently from these factors, which needed to be explored further in future studies.

We were unable to comment definitively on the cutoff point for age of onset associated with the preservation of $\beta$-cell function. Previous studies reported that adult-onset patients were more likely to retain residual $\beta$-cell function than juvenile-onset patients $(8,15)$. Williams (22) observed that those diagnosed before 5 years old were more likely to develop $\beta$-cell function failure. Wang (4) stratified subjects diagnosed from 1 to 56 years old according to their age of onset, and found those with an age of onset between 31-40 years retained the highest level of residual $\beta$-cell function. In our study, subjects were diagnosed between 2 to 60 years old. When stratified by different age of onset, we found that individuals diagnosed after 30 years old were more likely to retain residual $\beta$-cell function. While the RCS analysis showed that age of onset was positively and linearly associated with the possibility of $\beta$-cell function preservation, and no obvious cutoff point of age was found, which indicated larger sample size was needed to make the potential correlation between residual $\beta$-cell function and age of onset obvious. Therefore, although the abovementioned studies established the positive correlation between age of onset and $\beta$-cell function preservation, the complex relationship between specific age of onset and retention of $\beta$-cell function requires further investigation.

Although other clinical factors, including disease duration $(14,15,26)$, presence of autoantibodies $(22,27)$, sex (18), and HLA genotype (18) were reported to be associated with $\beta$-cell function in long-term patients with T1D, no significant associations were observed in our cases, suggesting possible ethnic differences.

The beneficial effects of residual $\beta$-cell function on
HbA1c and the risk of hypoglycemia have been well documented $(3,28,29)$. Furthermore, studies demonstrating that even marginal C-peptide levels, as low as $10 \mathrm{pmol} / \mathrm{L}$ or even $3.3 \mathrm{pmol} / \mathrm{L}$, were associated with improved glycemic control $(18,30)$, which was consistent with our results.

Unexpectedly, although residual $\beta$-cell function was associated with better glucose control, we did not find a correlation between persistent C-peptide and diabetic microvascular complications. Few studies have specifically focused on the relationship between chronic diabetic complications and residual $\beta$-cell function. The most wellknown report was released by the DCCT group, which reported that $\mathrm{C}$-peptide levels as low as $30 \mathrm{pmol} / \mathrm{L}$ were associated with reduced incidences of retinopathy and nephropathy (3) in patients with T1D. It was long believed that diabetic microvascular complications resulted largely from the high level and frequent fluctuation of blood sugar. Therefore, the beneficial effects associated with residual $\beta$-cell function may be partly due to the improvement of glycemia control, and partly to the direct protective effect of C-peptide on microvascular structure and function (31). Our negative results may be attributed to the relatively small difference of glycemia level in the distinct groups that failed to induce variation of complication status, considering the HbAlc levels in the DCCT study were $9.2 \%$ vs. $8.4 \%$ while they were $8.78 \%$ vs. $8.06 \%(64.6 \pm 20.3$ vs. $72.4 \pm 18.5 \mathrm{mmol} / \mathrm{mol})$ in our study. Moreover, the average disease duration in our study was longer than that in the DCCT study (13.0 vs. 8.2 years), which may mask the beneficial effect caused by other factors on the development of complications. Besides, our study comprised a relatively small number of participants, which makes the negative results difficult to interpret. Therefore, a larger sample size and whole-course studies are needed to further explore this issue.

The strengths of our study are as follows: (I) data from the present study is the first to provide strong evidence for the existence of a considerable level of residual $\beta$-cell function in Chinese long-term patients with T1D. This, together with the former data of the Caucasian populations, contributes to a deeper understanding of the natural history of T1D. The existence of residual $\beta$-cell function in long-term patients would help to expand the potential beneficiaries and to find novel intervention targets of the immune interventions, which aimed at protecting islet $\beta$-cells from autoimmune attacks. (II) We focused on adult-onset classical T1D. Different from Latent Autoimmune Diabetes in Adults (LADA), which is a subtype of slow-progressive autoimmune diabetes, classical T1D progresses more rapidly 
and faces more difficulties in clinical management. It was generally believed that classical T1D often occurs in children and adolescents, and LADA was the most common form of autoimmune diabetes in adults (32). But as was recently reported by Weng et al. (9), most new cases of classical T1D in China were adult-onset. This indicated that adult-onset is not necessarily to be 'latent'. Classical T1D among adults also deserves full of our consideration. Previous studies usually recruited patients from specific cohorts with certain limitations to their subjects, and the vast majority of studied patients were children or adolescent onset $(2,4,7,14)$. While the subjects in our study were from a population-based cohort with a mean age of onset of 19 years old, this was thought to be more representative of the T1D in general populations; (III) Distinct from previous studies, all the subjects in our study had at least one positive autoantibody, which robustly ensured the etiology homogeneity of the enrolled subjects. All the subjects were autoimmune-related, and idiopathic T1D were well excluded, which allowed this study to better align with the further exploration of immune interventions.

There were some limitations to our study. First, this was a single center study, and the relatively small sample size reduced the statistical power of the analyses and generate less precise estimates. Second, this was a retrospective study, and we were unable to adequately collect data at diagnosis or during the course of the disease. Third, the sensitivity of the C-peptide detection method needs to be improved further. And limited by the condition of the outpatient and the compliance of the patients, we only conducted a 2 -hour MMTT to evaluate patients' residual $\beta$-cell function. If possible, an arginine stimulation test should be used, and the monitored points of $\mathrm{C}$-peptide should be increased to maximize the detection limit of residual $\beta$-cell function. Besides, it is noteworthy that only three antibodies were detected in our study, and if conditions permit in the future, we will test more autoimmune indicators so as to maximumly include autoimmune T1D patients.

\section{Acknowledgments}

Funding: This work was supported by the National Key R\&D Program of China [2017YFC1309604 to Z Zhou, 2016YFC1305000 to Z Zhou] and the Natural Science Foundation of Hunan Province, China [2019JJ40419 to $\mathrm{Xia} \mathrm{Li].}$

\section{Footnote}

Reporting Checklist: The authors have completed the STROBE reporting checklist. Available at http://dx.doi. org/10.21037/atm-20-7471

Data Sharing Statement: Available at http://dx.doi. org/10.21037/atm-20-7471

Peer Review File: Available at http://dx.doi.org/10.21037/ atm-20-7471

Conflicts of Interest: All authors have completed the ICMJE uniform disclosure form (available at http://dx.doi. org/10.21037/atm-20-7471). The authors have no conflicts of interest to declare.

Ethical Statement: The authors are accountable for all aspects of the work in ensuring that questions related to the accuracy or integrity of any part of the work are appropriately investigated and resolved. The study was conducted in accordance with the Declaration of Helsinki (as revised in 2013). The study was approved by ethics committee of Second Xiangya Hospital (No. SCI-028-2016) and individual consent for this retrospective analysis was waived.

Open Access Statement: This is an Open Access article distributed in accordance with the Creative Commons Attribution-NonCommercial-NoDerivs 4.0 International License (CC BY-NC-ND 4.0), which permits the noncommercial replication and distribution of the article with the strict proviso that no changes or edits are made and the original work is properly cited (including links to both the formal publication through the relevant DOI and the license). See: https://creativecommons.org/licenses/by-nc-nd/4.0/.

\section{References}

1. Eisenbarth GS. Type I diabetes mellitus. A chronic autoimmune disease. N Engl J Med 1986;314:1360-8.

2. Keenan HA, Sun JK, Levine J, et al. Residual insulin production and pancreatic $\beta$-cell turnover after 50 years of diabetes: Joslin Medalist Study. Diabetes 2010;59:2846-53.

3. Steffes MW, Sibley S, Jackson M, et al. Beta-cell function and the development of diabetes-related complications in the diabetes control and complications trial. Diabetes Care 2003;26:832-6. 
4. Wang L, Lovejoy NF, Faustman DL. Persistence of prolonged C-peptide production in type 1 diabetes as measured with an ultrasensitive C-peptide assay. Diabetes Care 2012;35:465-70.

5. Oram RA, Jones AG, Besser RE, et al. The majority of patients with long-duration type 1 diabetes are insulin microsecretors and have functioning beta cells. Diabetologia 2014;57:187-91.

6. McGee P, Steffes M, Nowicki M, et al. Insulin secretion measured by stimulated C-peptide in long-established Type 1 diabetes in the Diabetes Control and Complications Trial (DCCT)/ Epidemiology of Diabetes Interventions and Complications (EDIC) cohort: a pilot study. Diabet Med 2014;31:1264-8.

7. Oram RA, McDonald TJ, Shields BM, et al. Most people with long-duration type 1 diabetes in a large populationbased study are insulin microsecretors. Diabetes Care 2015;38:323-8.

8. Uno S, Imagawa A, Kozawa J, et al. Complete loss of insulin secretion capacity in type $1 \mathrm{~A}$ diabetes patients during long-term follow up. J Diabetes Investig 2018;9:806-12.

9. Weng J, Zhou Z, Guo L, et al. Incidence of type 1 diabetes in China, 2010-13: population based study. BMJ 2018;360:;5295.

10. Alberti KG, Zimmet PZ. Definition, diagnosis and classification of diabetes mellitus and its complications. Part 1: diagnosis and classification of diabetes mellitus provisional report of a WHO consultation. Diabet Med 1998;15:539-53.

11. Luo S, Lin J, Xie Z, et al. HLA Genetic Discrepancy Between Latent Autoimmune Diabetes in Adults and Type 1 Diabetes: LADA China Study No. 6. J Clin Endocrinol Metab 2016;101:1693-700.

12. Chinese Diabetes Society. Guidelines for prevention and treatment of type 2 diabetes in Chinese (2017 edition). Chin J Diabetes Mellitus 2018;10:4-67.

13. American Diabetes Association. 5. Glycemic Targets. Diabetes Care 2016;39 Suppl 1:S39-46.

14. Palmer JP, Fleming GA, Greenbaum CJ, et al. C-peptide is the appropriate outcome measure for type 1 diabetes clinical trials to preserve beta-cell function: report of an ADA workshop, 21-22 October 2001. Diabetes 2004;53:250-64.

15. Davis AK, DuBose SN, Haller MJ, et al. Prevalence of detectable C-Peptide according to age at diagnosis and duration of type 1 diabetes. Diabetes Care 2015;38:476-81.

16. Greenbaum CJ, Anderson AM, Dolan LM, et al.
Preservation of beta-cell function in autoantibody-positive youth with diabetes. Diabetes Care 2009;32:1839-44.

17. Williams KV, Becker DJ, Orchard TJ, et al. Persistent C-peptide levels and microvascular complications in childhood onset type 1 diabetes of long duration. J Diabetes Complications 2019;33:657-61.

18. McKeigue PM, Spiliopoulou A, McGurnaghan S, et al. Persistent C-peptide secretion in Type 1 diabetes and its relationship to the genetic architecture of diabetes. BMC Med 2019;17:165.

19. McGuire HC, Ji L, Kissimova-Skarbek K, et al. Type 1 diabetes mellitus care and education in China: The 3C study of coverage, cost, and care in Beijing and Shantou. Diabetes Res Clin Pract 2017;129:32-42.

20. Jacobsen LM, Larsson HE, Tamura RN, et al. Predicting progression to type 1 diabetes from ages 3 to 6 in islet autoantibody positive TEDDY children. Pediatr Diabetes 2019;20:263-70.

21. Kasuga A, Maruyama T, Nakamoto S, et al. High-titer autoantibodies against glutamic acid decarboxylase plus autoantibodies against insulin and IA-2 predicts insulin requirement in adult diabetic patients. J Autoimmun 1999;12:131-5.

22. Williams GM, Long AE, Wilson IV, et al. Beta cell function and ongoing autoimmunity in longstanding, childhood onset type 1 diabetes. Diabetologia 2016;59:2722-6.

23. Karjalainen J, Salmela P, Ilonen J, et al. A comparison of childhood and adult type I diabetes mellitus. N Engl J Med 1989;320:881-6.

24. Effects of age, duration and treatment of insulindependent diabetes mellitus on residual beta-cell function: observations during eligibility testing for the Diabetes Control and Complications Trial (DCCT). The DCCT Research Group. J Clin Endocrinol Metab 1987;65:30-6.

25. Barker A, Lauria A, Schloot N, et al. Age-dependent decline of $\beta$-cell function in type 1 diabetes after diagnosis: a multi-centre longitudinal study. Diabetes Obes Metab 2014;16:262-7.

26. Dabelea D, Mayer-Davis EJ, Andrews JS, et al. Clinical evolution of beta cell function in youth with diabetes: the SEARCH for Diabetes in Youth study. Diabetologia 2012;55:3359-68.

27. Yu MG, Keenan HA, Shah HS, et al. Residual $\beta$ cell function and monogenic variants in long-duration type 1 diabetes patients. J Clin Invest 2019;129:3252-63.

28. Gibb FW, McKnight JA, Clarke C, et al. Preserved $\mathrm{C}$-peptide secretion is associated with fewer low-glucose 
events and lower glucose variability on flash glucose monitoring in adults with type 1 diabetes. Diabetologia 2020;63:906-14.

29. Rickels MR, Evans-Molina C, Bahnson HT, et al. High residual C-peptide likely contributes to glycemic control in type 1 diabetes. J Clin Invest 2020;130:1850-62.

30. Kuhtreiber WM, Washer SL, Hsu E, et al. Low levels of C-peptide have clinical significance for established Type 1 diabetes. Diabet Med 2015;32:1346-53.

31. Wahren J. C-peptide and the pathophysiology of microvascular complications of diabetes. J Intern Med 2017;281:3-6.

32. Zhou Z, Xiang Y, Ji L, et al. Frequency, immunogenetics, and clinical characteristics of latent autoimmune diabetes in China (LADA China study): a nationwide, multicenter, clinic-based cross-sectional study. Diabetes 2013;62:543-50.

Cite this article as: Cheng J, Yin M, Tang X, Yan X, Xie Y, He B, $\mathrm{LiX}$, Zhou Z. Residual $\beta$-cell function after 10 years of autoimmune type 1 diabetes: prevalence, possible determinants, and implications for metabolism. Ann Transl Med 2021;9(8):650. doi: $10.21037 /$ atm-20-7471 